\title{
Biosorption of lead from acid solution using chitosan as a supporting material for spore forming-fungal biomass encapsulation
}

\author{
W. Lang $\cdot$ W. Buranaboripan $\cdot$ J. Wongchawalit · \\ P. Parakulsuksatid $\cdot$ W. Vanichsriratana $\cdot$ N. Sakairi $\cdot$ \\ W. Pathom-aree $\cdot$ S. Sirisansaneeyakul
}

Received: 10 July 2011/Revised: 23 November 2011/Accepted: 12 January 2012/Published online: 28 February 2013

(C) CEERS, IAU 2013

\begin{abstract}
Asexual spores of the filamentous fungus Rhizopus arrhizus were used as the resting biomass as they tolerate chitosan gelling for mycelia growing in chitosan beads. Biosorption of lead using the dead detergent pretreated chitosan-immobilised and grown fungal beads was performed with initial lead (II) nitrate concentrations ranging from 9.02 to $281.65 \mathrm{mg} / \mathrm{L}$. The adsorption data were best correlated with equilibrium adsorption isotherms in the order Redlich-Peterson, Langmuir, Freundlich and Fritz-Schlünder by non-linear regression. The biosorption kinetic model of pseudo second-order $\left(R^{2}>0.99\right)$ fitted better than pseudo first-order and modified pseudo firstorder models. Among the four pseudo second-order kinetic models, the Blanchard model was the best fit for the experimental biosorption data. The rate-limiting step of biosorption of lead was shown to be intraparticle diffusion
\end{abstract}

W. Lang $(\bowtie) \cdot J$. Wongchawalit

Department of Microbiology, Faculty of Liberal Arts and

Science, Kasetsart University, Kampaeng Saen Campus,

Nakhonpathom 73140, Thailand

e-mail: weranuch@abs.agr.hokudai.ac.jp

W. Lang

Laboratory of Molecular Enzymology,

Research Faculty of Agriculture,

Hokkaido University, Kita 9, Nishi 9,

Kita-ku, Sapporo 060-8589, Japan

W. Buranaboripan

Department of Science, Faculty of Liberal Arts and Science,

Kasetsart University, Kampaeng Saen Campus,

Nakhonpathom 73140, Thailand

W. Buranaboripan · N. Sakairi

Graduate School of Environmental Science,

Hokkaido University, Kita-ku, Sapporo 060-0810, Japan controlled according to Weber and Morris model fitting. The beads could be regenerated using $1 \mathrm{M}$ nitric acid solution. This illustrated the good performance of the beads for regenerated sorption/desorption at least five cycles.

Keywords Adsorption kinetics - Detergent - Diffusion model $\cdot$ Heavy metal $\cdot$ Lead (II) $\cdot$ Regeneration $\cdot$ Rhizopus arrhizus

\section{Introduction}

Environmental pollution, especially with toxic heavy metals, is spreading throughout the world with industrial progress. The serious problem associated with heavy metals is caused by their accumulation in the food chain and their

\author{
P. Parakulsuksatid · W. Vanichsriratana $\cdot$ S. Sirisansaneeyakul \\ Department of Biotechnology, Faculty of Agro-Industry, \\ Kasetsart University, Bangkok 10900, Thailand \\ P. Parakulsuksatid · W. Vanichsriratana $\cdot$ S. Sirisansaneeyakul \\ Center for Advanced Studies in Tropical Natural Resources, \\ National Research University-Kasetsart University, \\ Kasetsart University, Chatuchak, Bangkok 10900, Thailand \\ W. Pathom-aree \\ Department of Biology, Faculty of Science, \\ Chiang Mai University, Chiang Mai 50200, Thailand
}


persistent nature (Pino et al. 2006a, b). Heavy metals such as mercury, cadmium, lead and chromium are very toxic to living organisms, even with exposure in small quantities. Their permissible limits in drinking water given by the World Health Organization are 1, 3, 10, and $50 \mu \mathrm{g} / \mathrm{L}$, respectively (WHO limits). Elevated levels of lead as $\mathrm{Pb}^{2+}$ ion can be traced to industrial discharges from a variety of sources such as electric battery manufacturing, lead smelting, and mining activities (Gavrilescu 2004; Sheng et al. 2004). In recent years, increased attention has been focused on the use of microorganisms in both living and non-living systems for the removal and possible recovery of metal ions from industrial wastes. Applications of the biosorption system may represent a potential alternative to existing technologies and offer enormous public health, and ecofriendly and cost benefits (Akpor and Muchie 2010).

Removal of heavy metals by chemical precipitation, adsorption, solvent extraction, etc. (Huang and Blankenship 1984; Crist et al. 1996) has significant disadvantages such as high reagent consumption, and the generation of toxic sludge or other by-products that need subsequent disposal (Bossrez et al. 1997). On the other hand, biosorption processes offer the advantages of low operating costs, possibility of metal recovery and potential biosorbent regeneration (Norton et al. 2004; Göksungur et al. 2005). A number of microbial and algal biomasses have been reported in the literature for their capacity to remove heavy metals (Ozdemir et al. 2003; Preetha et al. 2003; Deng et al. 2007). Among the various biosorption processes, fungal biosorption has been studied extensively because of the availability of filamentous fungi which are effective in the removal of heavy metals (Tsezos and Volosy 1982; Kapoor and Viraraghavan 1998; Preetha and Viruthagirl 2007; Bueno et al. 2008). Chitosan, a natural substance derived from chitin, was used in this study as the supporting material for living biomass immobilisation even though its anti-microbial and fungicide activity have been reported (Muňoz et al. 2009). The authors have previously reported the biosorption of nonylphenol, an endocrine disrupting compound onto the chitosan-immobilised and grown fungal beads produced by the resting spore form of $R$. $a r$ rhizus (Lang et al. 2009). It showed high affinity to absorb onto the beads. In this study, the authors investigated the functional properties of the beads using detergent modification for the biosorption of $\mathrm{Pb}^{2+}$ in a batch system. This is in particular to better understand the adsorption of $\mathrm{Pb}^{2+}$ ions during the uptake phase and the exchange with the solution at equilibrium. Experimental data of biosorption with different initial $\mathrm{Pb}^{2+}$ concentrations were fitted to various adsorption models. Two types of models were used, with isotherm models used to describe the equilibrium state, and kinetic models to describe the uptake phase. This research was carried out mainly at Kasetsart University (Nakhonpathom;
Thailand) and partially at Hokkaido University (Sapporo; Japan) during 2009-2011.

\section{Materials and methods}

\section{Microorganism}

Rice koji was used as the culture medium for the fungus. It was prepared by placing approximately $50 \mathrm{~g}$ Thai jasmine rice dampened with a little water in an Erlenmeyer flask in an autoclave at $121.5^{\circ} \mathrm{C}$ for $15 \mathrm{~min}$. R. arrhizus TISTR3606 was then grown on the sterilised rice koji at $30{ }^{\circ} \mathrm{C}$ for 7 days before sporangiospore harvesting. A stock of spore suspension with $3.7 \times 10^{9}$ spores $/ \mathrm{mL}$ was prepared and kept refrigerated at $4{ }^{\circ} \mathrm{C}$.

Preparation of the chitosan-immobilised and grown fungal beads

The beads were prepared following the method of Lang et al. (2009) as follows. The mixture of $2 \%(\mathrm{w} / \mathrm{v})$ chitosan in $9.0 \mathrm{~mL}$ of $3 \%(\mathrm{v} / \mathrm{v})$ aqueous acetic acid was gelled and then $200 \mu \mathrm{L}$ of the spore suspension was added. Subsequently, the solution was added dropwise to $3 \%(\mathrm{w} / \mathrm{v})$ sodium tripolyphosphate (TPP) solution $(100 \mathrm{~mL})$. The resulting mixture was stirred for $3 \mathrm{~h}$ before rinsing with distilled water to produce stable spherical beads. The beads were then transferred to a potato dextrose medium and cultivated at $30{ }^{\circ} \mathrm{C}$ in a rotary shaking incubator at $100 \mathrm{rpm}$. After 5 days of incubation, the chitosan-immobilised and grown fungal beads were harvested and made inactive by autoclaving at $100{ }^{\circ} \mathrm{C}$ for $10 \mathrm{~min}$. The chitosan-immobilised fungal beads ( $20 \mathrm{~g}$ wet weight) were pre-treated by boiling for $15 \mathrm{~min}$ in $50 \mathrm{~mL}$ of water in which $2.5 \mathrm{~g}$ of commercial laundry detergent (Omo, Unilever Thai Trading Co., Ltd) was dissolved (Kapoor and Viraraghavan 1998). The pre-treated beads were again washed several times with deionised water before freeze-drying and used as $\mathrm{Pb}^{2+}$ biosorbent throughout this study. Scanning electron microscope (SEM) observation was performed using the specimen preparation method of Pluemsab et al. (2007).

Metal solution preparation

A stock solution of $1.0 \mathrm{~g} / \mathrm{L}$ of $\mathrm{Pb}^{2+}$ was prepared from $\mathrm{Pb}\left(\mathrm{NO}_{3}\right)_{2}$ and deionised water that contained a few drops of $0.1 \mathrm{~mol} / \mathrm{L} \mathrm{HNO}_{3}$ to acidify the solution to prevent the precipitation of basic lead oxides. This solution was diluted as required to make working solutions. The initial $\mathrm{pH}$ of the working solution was adjusted to 5.0 by the addition of $\mathrm{HCl}$ or $\mathrm{NaOH}$ solution, except for the experiment 
examining the effect of $\mathrm{pH}$. Freshly prepared solution was used for each sorption experiment.

Effect of $\mathrm{pH}$ on the $\mathrm{Pb}^{2+}$ biosorption

Uptake of $\mathrm{Pb}^{2+}$ was determined at various $\mathrm{pH}$ between 1.0 and 6.0 of $130 \mathrm{mg} / \mathrm{L} \mathrm{Pb} \mathrm{Pb}^{2+}$ solution at $30{ }^{\circ} \mathrm{C}$. The biosorbent of $0.05 \mathrm{~g}$ was applied to the $50-\mathrm{mL}$ prepared solutions that were shaken at $100 \mathrm{rpm}$ on the rotary shaker for $6 \mathrm{~h}$ to ensure that equilibrium was reached.

Kinetic studies on the batch biosorption of $\mathrm{Pb}^{2+}$

Batch biosorption and kinetic studies were performed on the beads $(0.05 \mathrm{~g})$ suspended in $50 \mathrm{~mL}$ of solution, with five different initial $\mathrm{Pb}^{2+}$ ion concentrations of 9.03, 48.29, $103.95,199.96$, and $281.65 \mathrm{mg} / \mathrm{L}$. The flasks were kept on a rotary shaker at $100 \mathrm{rpm}$ and $30{ }^{\circ} \mathrm{C}$. Samples were withdrawn at appropriate time intervals and centrifuged at $12,000 \mathrm{rpm}(14,000 \times g)$ for $5 \mathrm{~min}$ to collect the supernatant. The concentration of metal ions in the supernatant was analysed using flame atomic absorption spectrophotometry (Varian spectrAA-220 Fast Sequential). Each five sample set was repeated and the results given are the average values. The $\mathrm{Pb}^{2+}$ uptake $(q, \mathrm{mg} / \mathrm{g})$ was determined by using the following equation:

$q=\frac{\left(C_{0}-C_{e}\right) V}{W}$

where, $C_{0}$ is the initial concentration of $\mathrm{Pb}^{2+}(\mathrm{mg} / \mathrm{L}), C_{e}$ is the concentration of $\mathrm{Pb}^{2+}$ at equilibrium, $V$ is the volume $(\mathrm{L})$, and $W$ is the biosorbent weight $(\mathrm{g})$.

\section{Isotherm models}

Modelling of the equilibrium state of adsorption improves understanding of the factors that affect the capacity of the adsorbent and the affinity for $\mathrm{Pb}^{2+}$ ions. It can help describe the distribution and form of active sites on the adsorbent and complement the kinetic study. Four adsorption isotherms were used in this study.

The Langmuir model for monolayer adsorption on a homogeneous surface, with a finite number of binding sites and few interactions between adsorbed molecules (Aksu and Balibek 2007), gives the equation:

$q=\frac{Q_{0} b C_{e}}{1+b C_{e}}$

where $Q_{0}$ is the Langmuir adsorption isotherm constant $(\mathrm{mg} / \mathrm{g})$ and $b$ is Langmuir isotherm constant $(\mathrm{L} / \mathrm{mg})$. The Langmuir constant $Q_{0}$ is often used to compare the performance of biosorbents, while the other constant $b$ characterises the initial slope of the isotherm. Thus, for a good biosorbent, the $Q_{0}$ is high and the initial isotherm slope is steep.

The Freundlich model for monolayer sorption on a heterogeneous energetic distribution of active sites, with interactions between adsorbed molecules (Aksu et al. 1997; Aksu 2001), gives the equation:

$q=k_{F} C_{e}^{1 / n}$

where $k_{F}$ is the Freundlich constant characteristic of the system related to the adsorption capacity $(\mathrm{mg} / \mathrm{g})(\mathrm{L} / \mathrm{mg})^{1 / n}$, and $1 / n$ is a heterogeneity factor, which is a measure of affinity of the adsorbed molecules for the sorbents, and is less than 1 . The adsorption process is then favourable.

The Redlich and Peterson model gives an Eq. (4) with three constant parameters that incorporates the models of Langmuir and Freundlich.

$q=\frac{k_{R} C_{e}}{1+a_{R} C_{e}^{\beta}}$

where $\beta$ is dimensionless and reflects the heterogeneity of the binding surface, with values ranging between 0 and 1 . For $\beta=1$, the Redlich-Peterson model converts to the Langmuir model form (Aksu 2001). $k_{R}$ and $a_{R}$ are the Redlich-Peterson constants.

The Fritz-Schlünder model for single-component systems has better flexibility for fitting experimental data, since it contains more parameters than other equilibrium isotherms (Fritz and Schlünder 1974; Yang and Al-Duri 2005) and is usually given as:

$q=\frac{k_{S} C_{e}^{b_{1}}}{1+a_{S} C_{e}^{b_{2}}}$

where, $k_{S}, a_{S}, b_{1}$, and $b_{2}$ are the Fritz and Schlünder isotherm constants.

Kinetic models

To investigate the kinetics of adsorption, the adsorption rate of $\mathrm{Pb}^{2+}$ was measured with different initial $\mathrm{Pb}^{2+}$ concentrations and fitted to the proposed models mentioned below. This determines the rate-limiting step in adsorption, how it is affected by the concentration of $\mathrm{Pb}^{2+}$, and ultimately finds the optimal conditions for use effectively on adsorbents.

The pseudo first-order kinetic model based on solid capacity gives a linear and non-linear form in Eqs. (6) and (7), respectively.

$\log \left(q_{e}-q\right)=\log q_{e}-\frac{K_{1} t}{2.303}$

$q=q_{e}\left(1-e^{-K_{1} t}\right)$ 
This model is applicable if a plot of $\log \left(q_{e}-q\right)$ versus time is linear. Also, a modified pseudo first-order kinetic model with an improved rate constant (Ho and Mckay 2000), gives:

$\frac{q}{q_{e}}+\ln \left(q_{e}-q\right)=\ln q_{e}-K_{2} t$

With this equation, a plot of $q / q_{e}+\ln \left(q_{e}-q\right)$ against $t$ should be linear.

In comparison, the pseudo second-order kinetic model gives a linear and non-linear form as in Eqs. (9) and (10), respectively:

$\frac{t}{q}=\frac{1}{K_{3} q_{e}^{2}}+\frac{t}{q_{e}}$

$q=\frac{q_{e}^{2} K_{3} t}{1+q_{e} K_{3} t}$

If the second-order kinetics is applicable, the plot of $t / q$ versus $t$ should give a linear relationship (Ho and Mckay 2000). The initial sorption rate $(h ; \mathrm{mg} / \mathrm{g} \mathrm{min})$ is then determined by:

$h=K_{3} q_{e}^{2}$

In addition, the other three pseudo second-order models, from Sobkowsk and Czerwiński (1974), Blanchard et al. (1984) and Ritchie (1977), give the following Eqs. (12-14), respectively, where $\theta=q / q_{e}$ and $\alpha=1 / q_{e}$ (Ho 2006; Kumar 2007):

$\frac{\theta}{1-\theta}=K_{4} t$

$\frac{1}{q_{e}-q}-\alpha=K_{5} t$

$\frac{q_{e}}{q_{e}-q}=K_{6} t+1$

Intraparticle diffusion model

The intraparticle diffusion model assumes that the film diffusion is negligible and intraparticle diffusion is the only rate-limiting step (Yang and Al-Duri 2005). The model simplified from Weber-Morris method (Nadavala et al. 2009) is expressed as:

$q=k_{p} t^{0.5}$

where $k_{p}\left(\mathrm{mg} / \mathrm{g} \mathrm{min}{ }^{-0.5}\right)$ is defined as the intraparticle diffusion rate constant.

\section{Characterisation of the biosorbent}

FT-IR spectra of (a) chitosan-immobilised and grown fungal beads with metal load of $\mathrm{Pb}^{2+}$ ion, (b) chitosan-immobilised and grown fungal beads without metal loaded, and (c) chitosan-immobilised and grown fungal beads pre-treated with commercial laundry detergent without metal loaded were obtained by using a FT-IR spectrophotometer (Jasco FT/IR 460 Plus, Japan) in the range $4,000-700 \mathrm{~cm}^{-1}$ using $\mathrm{KBr}$ discs.

Desorption and regeneration studies

Metal desorption studies were performed on the beads $(0.05 \mathrm{~g})$ suspended in $50 \mathrm{~mL}$ of $\mathrm{Pb}^{2+}$ solution at the $C_{0}=109.48 \mathrm{mg} / \mathrm{L}$. After the adsorption experiment, the beads were collected by filtration and transferred to $50 \mathrm{~mL}$ different desorbent solutions, such as $1 \mathrm{M}$ of hydrochloric acid $(\mathrm{HCl})$, nitric acid $\left(\mathrm{HNO}_{3}\right)$, sulfuric acid $\left(\mathrm{H}_{2} \mathrm{SO}_{4}\right)$, sodium hydroxide $(\mathrm{NaOH})$, calcium chloride $\left(\mathrm{CaCl}_{2}\right)$, sodium carbonate $\left(\mathrm{Na}_{2} \mathrm{CO}_{3}\right)$, ethylenediaminetetraacetic acid (EDTA) and deionised water. The flasks were kept on a rotary shaker, the speed of which was controlled at $100 \mathrm{rpm}$ and $30^{\circ} \mathrm{C}$. Samples were withdrawn at the appropriate time intervals and then centrifuged to collect the supernatant. The concentrations of $\mathrm{Pb}^{2+}$ in the supernatant were analysed.

To evaluate the feasibility of using the chitosan-immobilized and grown fungal beads for successive adsorptiondesorption cycles, a pre-weighed biomass $(0.05 \mathrm{~g})$ suspended in $50 \mathrm{~mL}$ of $109.48 \mathrm{mg} / \mathrm{L} \mathrm{Pb}^{2+}$ solution was kept on a rotary shaker at $100 \mathrm{rpm}$ and $30^{\circ} \mathrm{C}$ for $360 \mathrm{~min}$. Thereafter, the metal-loaded beads were collected and suspended in $50 \mathrm{~mL}$ of $1 \mathrm{M} \mathrm{HNO}_{3}$ to recover the adsorbed metal. After incubation for $360 \mathrm{~min}$, the beads were withdrawn and centrifuged to collect the supernatant and determine the concentration of $\mathrm{Pb}^{2+}$. The regenerated biosorbent was washed with deionised water to remove excess of acid before freeze-drying and thereafter resuspended in the $\mathrm{Pb}^{2+}$ solution for the next adsorption. Adsorption and desorption of $\mathrm{Pb}^{2+}$ were performed for five cycles.

\section{Statistical analyses}

The kinetic expression with the best fit to the experimental data was determined using the coefficient of correlation, $R^{2}$ (Kumar 2007), which is defined as:

$R^{2}=\frac{\sum\left(q_{\mathrm{cal}}-\bar{q}_{\text {exp }}\right)^{2}}{\sum\left(q_{\mathrm{cal}}-\bar{q}_{\mathrm{exp}}\right)^{2}+\sum\left(q_{\mathrm{cal}}-q_{\mathrm{exp}}\right)^{2}}$

where $q_{\text {cal }}$ is the theoretical $\mathrm{Pb}^{2+}$ uptake $(\mathrm{mg} / \mathrm{g}), q_{\text {exp }}$ is the experimental $\mathrm{Pb}^{2+}$ uptake $(\mathrm{mg} / \mathrm{g})$ and $\bar{q}_{\text {exp }}$ is the average experimental $\mathrm{Pb}^{2+}$ uptake $(\mathrm{mg} / \mathrm{g})$. A high value of $R^{2}$ is perceived as implying a causal relationship between the variables. 
Also, the non-normalised root mean square (RMS) that weights the actual error at all points (Yang and Al-Duri 2005) was also used and is defined as:

Non-normalised RMS $=\sqrt{\frac{\sum_{i=1}^{N}\left(q_{c a l}-q_{\exp }\right)^{2}}{N}}$

where, $N$ is the number of sample. A lower non-normalised RMS value indicated greater similarity between the variables. All statistical data analysis was performed with the help of the toolbox present in Microsoft ${ }^{\circledR}$ Excel (Microsoft Corporation, USA).

\section{Results and discussion}

Properties of the chitosan-immobilised and grown fungal beads

SEM images revealed the mycelial morphology of the beads (Fig. 1). The cross-sectional image indicated dense uniform fungal growth inside the bead, with outgrowing mycelia covering the whole particle surface (Fig. 1a). The bead surface was completely covered by homogeneously distributed exuberant mycelia (Fig. 1b). The diameters of the dried beads were approximately $4 \mathrm{~mm}$, which was about three times larger than the plain beads. Although chitosan is a natural fungicide that has been used to inhibit fungal growth of several species such as Collectotrichum sp. (Muňoz et al. 2009), this immobilising approach indicated that some fungal spores could tolerate the chitosan gelling condition because of their extra thick cell wall.

Although there are a number of immobilisation methods which start with grinding dead fungal mycelia with a mortar and pestle before immobilisation in a polymer matrix (Preetha and Viruthagirl 2007), the immobilisation method reported here better facilitated a high production yield of fungal biomass, as it germinated in the chitosan gel and the cultivation was simple. There was also a stronger affinity between solute and biosorbent as there was direct exposure without any intervening barrier. These beads were also more stable than plain chitosan beads when immersed in acidic solutions, even at $\mathrm{pH}=1$.

\section{Effect of $\mathrm{pH}$ on the $\mathrm{Pb}^{2+}$ biosorption}

An initial $\mathrm{pH}$ effect on the biosorption of $\mathrm{Pb}^{2+}$ ion was conducted varying from 1.0 to 6.0 . Biosorbtion of $\mathrm{Pb}^{2+}$ was found to be $\mathrm{pH}$ dependent. Uptake of $\mathrm{Pb}^{2+}$ increased from 87 to $100 \%$ as initial $\mathrm{pH}$ increased from 1.0 to 5.0 and then slightly decreased to $96 \%$ at $\mathrm{pH}$ 6.0. This is explained by the fact that the $\mathrm{pH}$ of the solution affected the ionic interaction between metal ions and functional
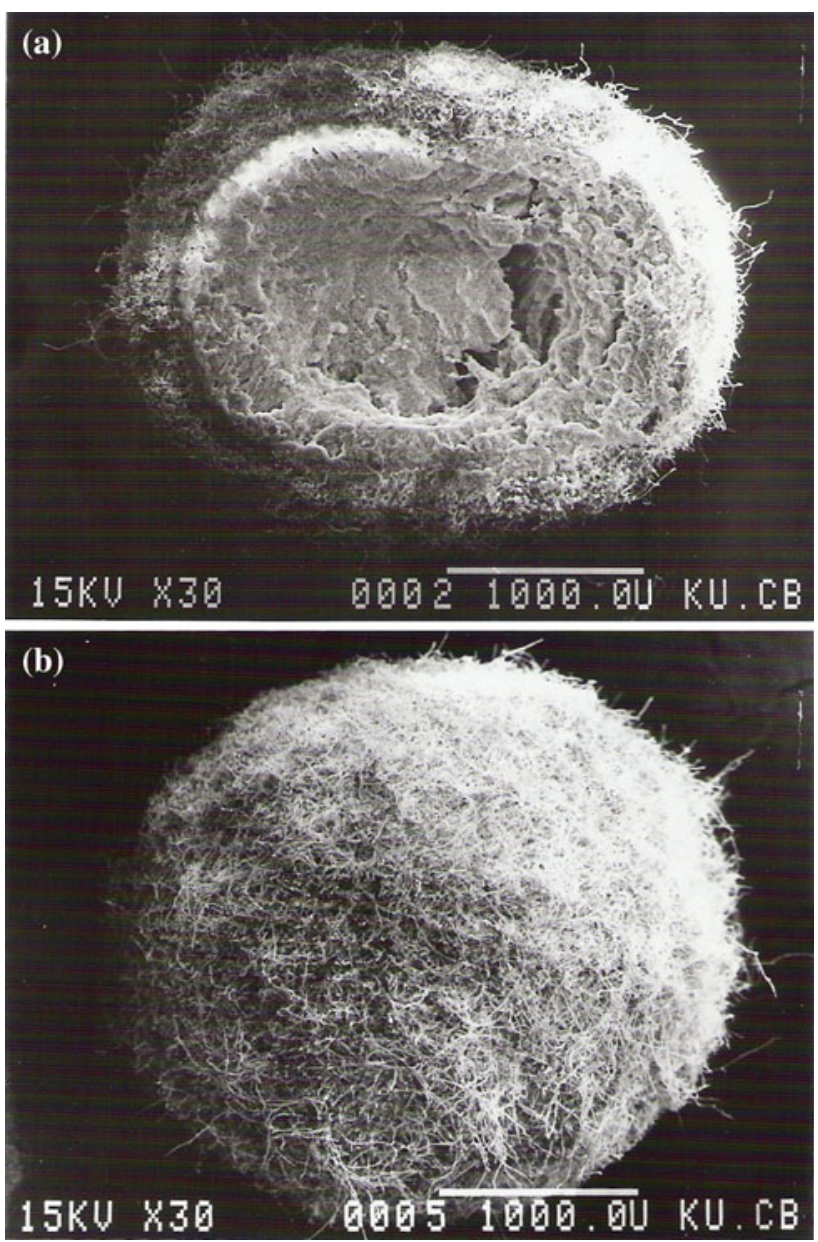

Fig. 1 SEM images of a surface-boundary cross section and $\mathbf{b}$ surface of the chitosan-immobilised and grown Rhizopus arrhizus bead

groups on the biomass, especially the ionisation state of the functional groups, i.e. carboxylate, phosphate and amino groups on the fungal cell wall (Arica et al. 2003). Accordingly, the high proton concentration found at lower $\mathrm{pH}$ decreased cationic heavy metal biosorption due to the positive charge density on metal binding sites. For example, hydrogen ions compete effectively with metal ions in binding to the sites. When the initial $\mathrm{pH}$ increased, the negative charge density on the cell surface also increased as a result of deprotonation of the metal binding sites. Therefore, the metal ions then compete more effectively at the available binding sites to increase biosorption (Akar and Tunali 2006).

The effect of contact time and initial $\mathrm{Pb}^{2+}$ concentrations on $\mathrm{Pb}^{2+}$ biosorbtion was investigated for five different initial $\mathrm{Pb}^{2+}$ concentrations varying in the range of 9.03$281.65 \mathrm{mg} / \mathrm{L}$ at $\mathrm{pH} 5.0$ and $30^{\circ} \mathrm{C}$. The uptake of $\mathrm{Pb}^{2+}$ was rapid in the first $20 \mathrm{~min}$ at the low $\mathrm{Pb}^{2+}$ concentrations of $9.02,48.28$ and $103.95 \mathrm{mg} / \mathrm{L}$, and then attained equilibrium at about $150 \mathrm{~min}$. As the initial concentration of $\mathrm{Pb}^{2+}$ 
increased from 199.96 to $281.65 \mathrm{mg} / \mathrm{L}$, equilibrium was shortly attained after $180 \mathrm{~min}$. The $\mathrm{Pb}^{2+}$ uptake at equilibrium $q_{e}$ increased from 9.02, 41.28, 86.01, 155.63 and $208.30 \mathrm{mg} / \mathrm{g}$ with increase in initial $\mathrm{Pb}^{2+}$ concentration from 9.03 to $281.65 \mathrm{mg} / \mathrm{L}$, respectively. A similar result was reported by Okoye et al. (2010) for the adsorption of $\mathrm{Pb}^{2+}$ onto fluted pumpkin seed shell-activated carbon.

\section{Adsorption equilibrium}

The biosorption data were fitted to the four adsorption isotherms of Langmuir, Freundlich, Redlich-Peterson and Fritz-Schlünder (Fig. 2). The adsorption isotherm constants of $\mathrm{Pb}^{2+}$ with the corresponding correlation coefficients $\left(R^{2}\right)$ and non-normalised RMS are presented in Table 1. The Redlich-Peterson model yielded a good fit to the experimental data with both the highest $R^{2}$ value of 0.9999 and a non-normalised RMS of 0.4629 , which was the only one less than 1 . The $\beta$ value shown in Table 1 is 0.6970 , which lies between 0 and 1 indicating that the biosorbent was well adsorbed by $R$. arrhizus (Preetha and Viruthagirl 2007). The biosorption system of $\mathrm{Pb}^{2+}$ on the

Table 1 Adsorption equilibrium constants for the biosorption of $\mathrm{Pb}^{2+}$ by dead chitosan-immobilised and grown fungal beads

\begin{tabular}{lc}
\hline Langmuir constants & \\
$Q_{0}(\mathrm{mg} / \mathrm{g})$ & 381.23 \\
$b(\mathrm{~L} / \mathrm{mg})$ & 0.0160 \\
$R^{2}$ & 0.9993 \\
Non-normalised RMS & 2.2591 \\
Freundlich constants & \\
$k_{F}(\mathrm{mg} / \mathrm{g})(\mathrm{L} / \mathrm{mg})^{1 / n}$ & 12.3550 \\
$n$ & 0.6610 \\
$R^{2}$ & 0.9980 \\
Non-normalised RMS & 3.6988 \\
Redlich-Peterson constants & \\
$k_{R}(\mathrm{~L} / \mathrm{g})$ & 8.0840 \\
$a_{R}$ & 0.0930 \\
$\beta$ & 0.6970 \\
$R^{2}$ & 0.9999 \\
Non-normalised RMS & 0.4629 \\
Fritz-Schlünder constants & \\
$k_{S}(\mathrm{mg} / \mathrm{g})(\mathrm{mg} / \mathrm{L})^{-b_{1}}$ & 8.3567 \\
$a_{S}(\mathrm{mg} / \mathrm{L})^{-b_{2}}$ & 0.1767 \\
$b_{1}$ & 0.8379 \\
$b_{2}$ & 0.1868 \\
$k_{S} / a_{S}$ & 47.2931 \\
$R^{2}$ & 0.9978 \\
Non-normalised RMS & 9.3009
\end{tabular}

Parameters estimated using linear regression performed with Microsoft $^{\circledR}$ Excel (Microsoft Corporation, USA) green alga Pithophora oedogonia was reported to also be well modelled by the Redlich-Peterson isotherm, with $\beta=1.76$ (Singh et al. 2008).

Although the Redlich-Peterson isotherm was suitable as a design model for the biosorption system, Langmuir and Freundlich adsorption isotherms are still useful for appropriately refining the sorption characteristics. Based on the Freundlich isotherm plot, the adsorption capacity, $k_{F}=$ $12.35(\mathrm{mg} / \mathrm{g})(\mathrm{L} / \mathrm{mg})^{1 / n}$, and the adsorption intensity, $n=0.66$, were obtained. From the Langmuir isotherm, the adsorption capacity, $Q_{0}=381.23 \mathrm{mg} / \mathrm{g}$, and the Langmuir constant, $b=0.016 \mathrm{~L} / \mathrm{mg}$, were obtained. The $Q_{0}$ was compared to the other adsorbents as shown in Table 2. The $Q_{0}$ of the beads was obviously higher than other biosorbents and also their small value of $b$ indicates the great affinity for $\mathrm{Pb}^{2+}$ biosorption (Arica et al. 2003).

\section{Kinetic modelling}

The experimental specific uptake of $\mathrm{Pb}^{2+}$ was compared with the Lagergren pseudo first-order, the modified pseudo first-order and the pseudo second-order kinetic equations as shown in Table 3, with the linear correlation of the experimental data.

The $R^{2}$ values obtained for the pseudo first-order and the modified pseudo first-order kinetic equations were lower than the values obtained with the pseudo second-order kinetics equation. Therefore, the pseudo second-order model better represents the sorption kinetics and thus supports the assumption that the overall adsorption rate is proportional to the square of the difference between the equilibrium $\mathrm{Pb}^{2+}$ uptake and the actual uptake amount $\left(q_{e}-\mathrm{q}\right)^{2}$ (Yang and Al-Duri 2005). This suggests that the overall rate of the $\mathrm{Pb}^{2+}$ biosorption process is controlled by a chemical process as the rate-controlling mechanism. An external surface mass transfer or film diffusion process possibly controls the early stages of the adsorption process. This might be followed by a slowdown of diffusion stage (Bayramoğlu and Arica 2006).

It was observed that the pseudo second-order rate constants $K_{3}$ increased with increasing $C_{0}$ from 9.02 to $103.95 \mathrm{mg} / \mathrm{L}$, whereas $K_{3}$ decreased clearly with further increases in $C_{0}$ from 199.96 to $281.65 \mathrm{mg} / \mathrm{L}$. This was similar to the $K_{1}$ and $K_{2}$ for the pseudo first-order and the modified pseudo first-order kinetic equations. A larger rate constant implies that less time is needed for the sorption system to reach the same fractional uptake (Ghodbane and Hamdaoui 2008). Therefore, the trend of increasing $K_{3}$ with increasing $C_{0}$ to $103.95 \mathrm{mg} / \mathrm{L}$ revealed that the system was the fastest for sorption when $C_{0}$ was approximately $100 \mathrm{mg} / \mathrm{L}$. Increasing $C_{0}$ further would not accelerate fractional uptake. Table 3 summarises the results obtained by fitting experimental data to various pseudo second-order 
Table $2 \mathrm{~Pb}^{2+}$ uptake capacity (Langmuir $Q_{0}$ ) of various adsorbents

\begin{tabular}{lccl}
\hline Adsorbent & $Q_{o}(\mathrm{mg} / \mathrm{g})$ & $\mathrm{pH}$ & References \\
\hline Powder activated carbon & 26.94 & 5.0 & An et al. (2001) \\
Amberlite IRC-718 & 290.08 & 4.8 & Vaughan et al. (2001) \\
Amberlite 200 & 352.24 & 4.8 & Vaughan et al. (2001) \\
Chondrus crispus & 194.97 & 3.5 & Holan and Volesky (1994) \\
Cladophora fascicularis & 198.50 & 5.0 & Deng et al. (2007) \\
Streptomyces longwoodensis & 100.00 & 3.0 & Friis and Myers-Keith (1986) \\
Aspergillus flavus & 13.5 & 5.0 & Akar and Tunali (2006) \\
Rhizopus arrhizus & 15.5 & 5.0 & Sag et al. (1995) \\
Amanita rubescens & 38.4 & 5.0 & Sari and Tuzen (2009) \\
Chitosan-immobilised and grown fungal beads & 381.23 & 5.0 & Present study \\
\hline
\end{tabular}

Table 3 Comparison of the linearised forms of pseudo first-, modified first-, and pseudo second-order kinetic models for biosorption of $\mathrm{Pb}^{2+}$ with varying initial $\mathrm{Pb}^{2+}$ concentrations

\begin{tabular}{|c|c|c|c|c|c|c|c|c|c|c|}
\hline \multicolumn{2}{|l|}{$\mathrm{Pb}^{2+}$} & \multicolumn{3}{|c|}{ Pseudo first-order rate } & \multicolumn{3}{|c|}{ Modified pseudo first-order rate } & \multicolumn{3}{|c|}{ Pseudo second-order rate (Ho and Mckay) } \\
\hline $\begin{array}{l}C_{0} \\
(\mathrm{mg} / \mathrm{L})\end{array}$ & $\begin{array}{l}q_{e, \exp } \\
(\mathrm{mg} / \mathrm{g})\end{array}$ & $\begin{array}{l}K_{1} \\
\left(\min ^{-1}\right)\end{array}$ & $\begin{array}{l}q_{e, \mathrm{cal}} \\
(\mathrm{mg} / \mathrm{g})\end{array}$ & $R^{2}$ & $\begin{array}{l}K_{2} \\
\left(\min ^{-1}\right)\end{array}$ & $\begin{array}{l}q_{e, \mathrm{cal}} \\
(\mathrm{mg} / \mathrm{g})\end{array}$ & $R^{2}$ & $\begin{array}{l}K_{3} \\
(\mathrm{~g} / \mathrm{mg} \min )\end{array}$ & $\begin{array}{l}q_{e, \mathrm{cal}} \\
(\mathrm{mg} / \mathrm{g})\end{array}$ & $R^{2}$ \\
\hline 9.03 & 9.02 & $9.21 \times 10^{-4}$ & 1.12 & 0.4315 & $5.10 \times 10^{-3}$ & 10.25 & 0.8827 & $6.11 \times 10^{-4}$ & 12.36 & 0.9492 \\
\hline 48.29 & 41.28 & $6.45 \times 10^{-3}$ & 24.92 & 0.8949 & $4.60 \times 10^{-3}$ & 38.49 & 0.9041 & $9.22 \times 10^{-4}$ & 39.37 & 0.9214 \\
\hline 103.95 & 86.01 & $1.08 \times 10^{-2}$ & 31.67 & 0.8745 & $9.60 \times 10^{-3}$ & 61.92 & 0.9042 & $1.04 \times 10^{-3}$ & 86.96 & 0.9264 \\
\hline 199.96 & 155.63 & $1.04 \times 10^{-2}$ & 76.88 & 0.8747 & $8.80 \times 10^{-3}$ & 137.54 & 0.9018 & $3.70 \times 10^{-4}$ & 156.25 & 0.9211 \\
\hline 281.65 & 208.30 & $3.45 \times 10^{-3}$ & 105.05 & 0.8606 & $2.20 \times 10^{-3}$ & 171.52 & 0.8858 & $3.60 \times 10^{-4}$ & 172.41 & 0.9060 \\
\hline
\end{tabular}

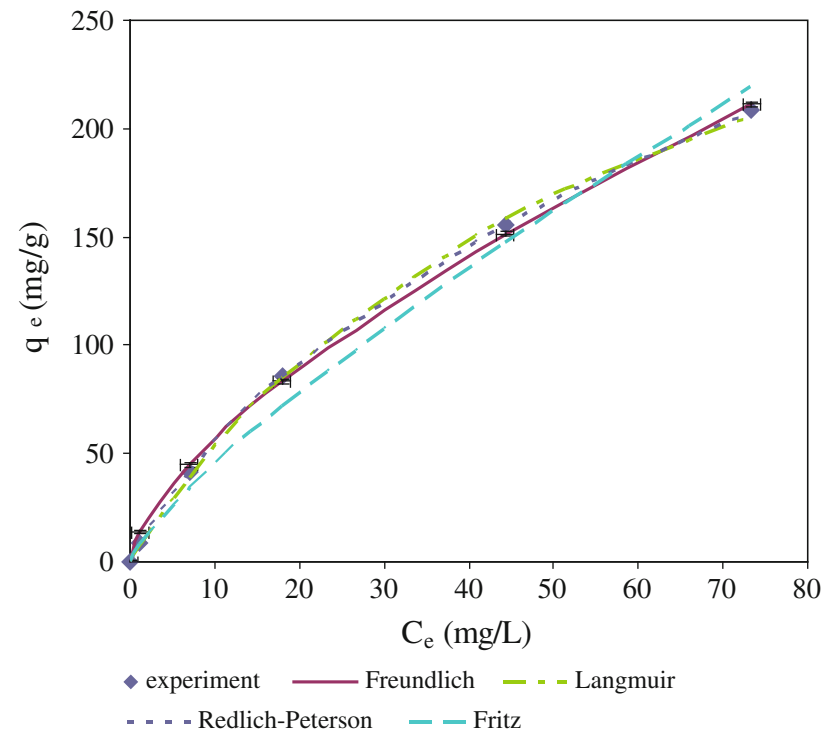

Fig. 2 Comparison of various adsorption isotherms for $\mathrm{Pb}^{2+}$ by the chitosan-immobilised and grown fungal beads at $30{ }^{\circ} \mathrm{C}$

kinetic models using linearised and non-linearised forms, i.e. Sobkowsk and Czerwiński (1974), Ritchie (1977), Blanchard et al. (1984) and Ho and Mckay (2000) models. Among them, the Blanchard model yielded a much better

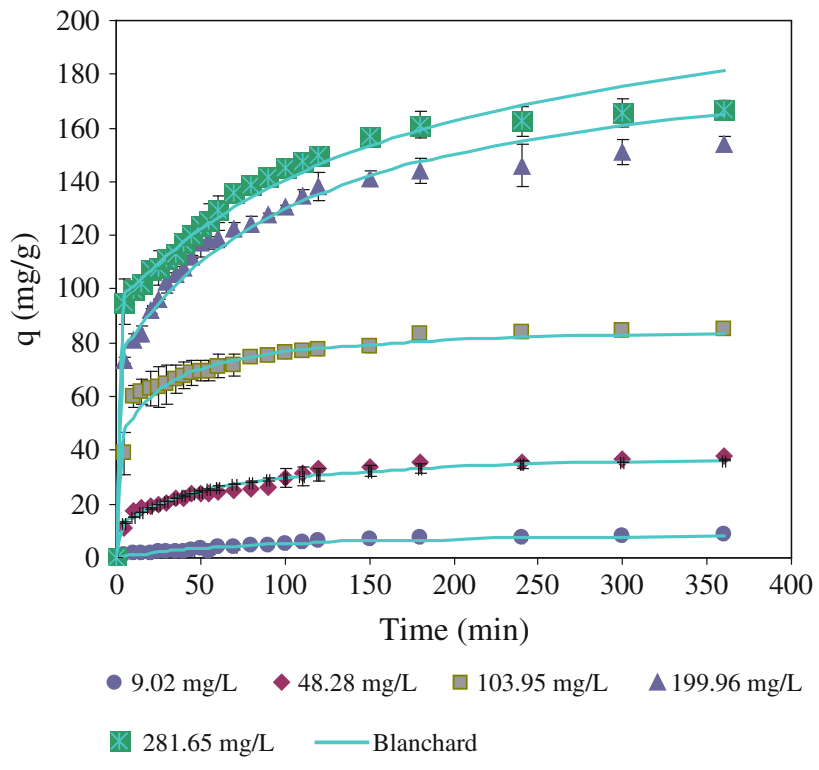

Fig. 3 The best fit of adsorption kinetic models of $\mathrm{Pb}^{2+}$ at $30{ }^{\circ} \mathrm{C}$

fit than the other models for the biosorption of $\mathrm{Pb}^{2+}$ for the entire range of $\mathrm{C}_{0}$ when using a non-linear curve fitting method included in the solver add-in with the Microsoft Excel spreadsheet package (Fig. 3) (Table 4). 


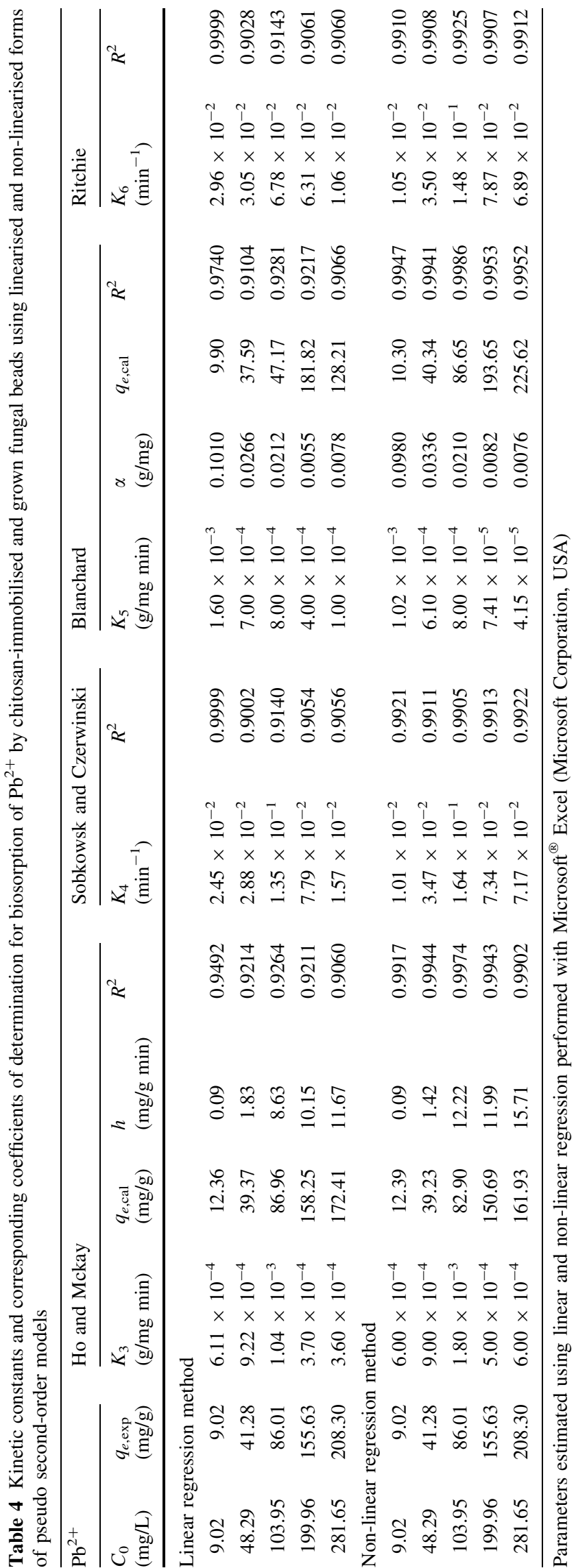

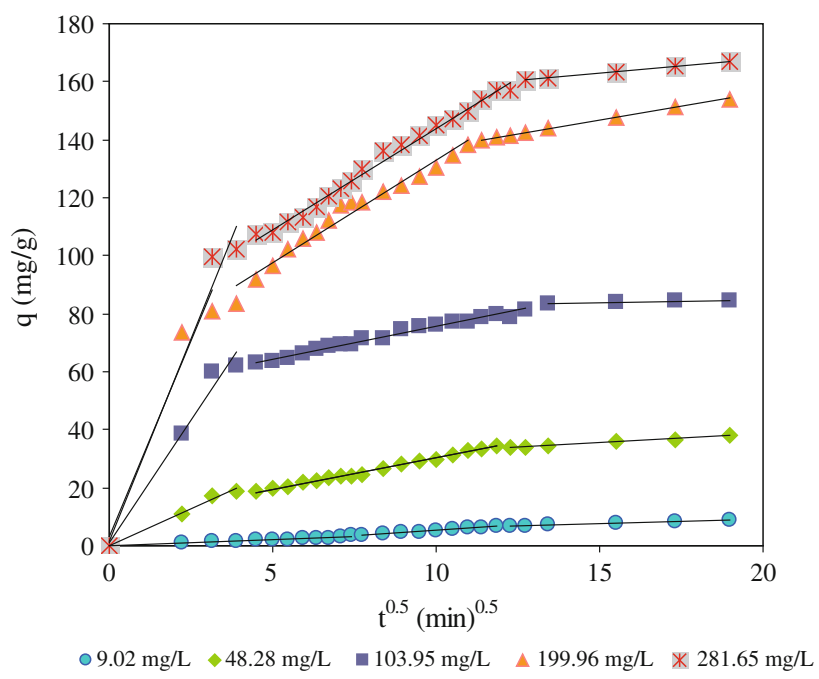

Fig. 4 Modelling of intraparticle diffusion at different $C_{0}$, ranging from 9.02 to $281.65 \mathrm{mg} / \mathrm{L}$

Intraparticle diffusion model

The intraparticle diffusion plots according to the WeberMorris method present two successive linear regions; the intraparticle diffusion rate, constant $k_{p}$ and $\mathrm{R}^{2}$ can be obtained from the slope of the plot (Nadavala et al. 2009). The plot should be linear if intraparticle diffusion is involved in the biosorption process; if the line passes through the origin, it indicates that intraparticle diffusion is only the rate-controlling step (Yang and Al-Duri 2005). However, if the value of the intercept is obtained, it will give an idea about the boundary layer thickness, the larger the intercept, the greater is the boundary layer effect $(\mathrm{Na}-$ davala et al. 2009).

According to these studies, the intraparticle diffusion plot represents multilinear plots in which the different stages are involved in adsorption. Figure 4 shows the plots of $q$ versus $t^{0.5}$ for different $C_{0}$, ranging from 9.02 to $281.65 \mathrm{mg} / \mathrm{L}$. It can be observed that the straight line does not pass through the origin; therefore, intraparticle diffusion was not only the rate-controlling step. The first steep linear slope implies that the diffusion in bulk phase to the exterior surface of the biosorbent starts the fastest. The second portion describes the diffusion into macropores. The third portion shows the lowest slope of adsorption into micropores and the final equilibrium stage where the intraparticle diffusion starts to slow down due to the extremely low $\mathrm{Pb}^{2+}$ concentration in the solution. This implied that the intraparticle diffusion of $\mathrm{Pb}^{2+}$ ions into macropores was the rate-limiting step in the adsorption process in the chitosan-immobilised and grown fungal beads. Table 5 summarises the values of kinetic parameters and correlation coefficients, showing that the rate constant, $k_{p}$ increases with increasing $C_{0}$. 

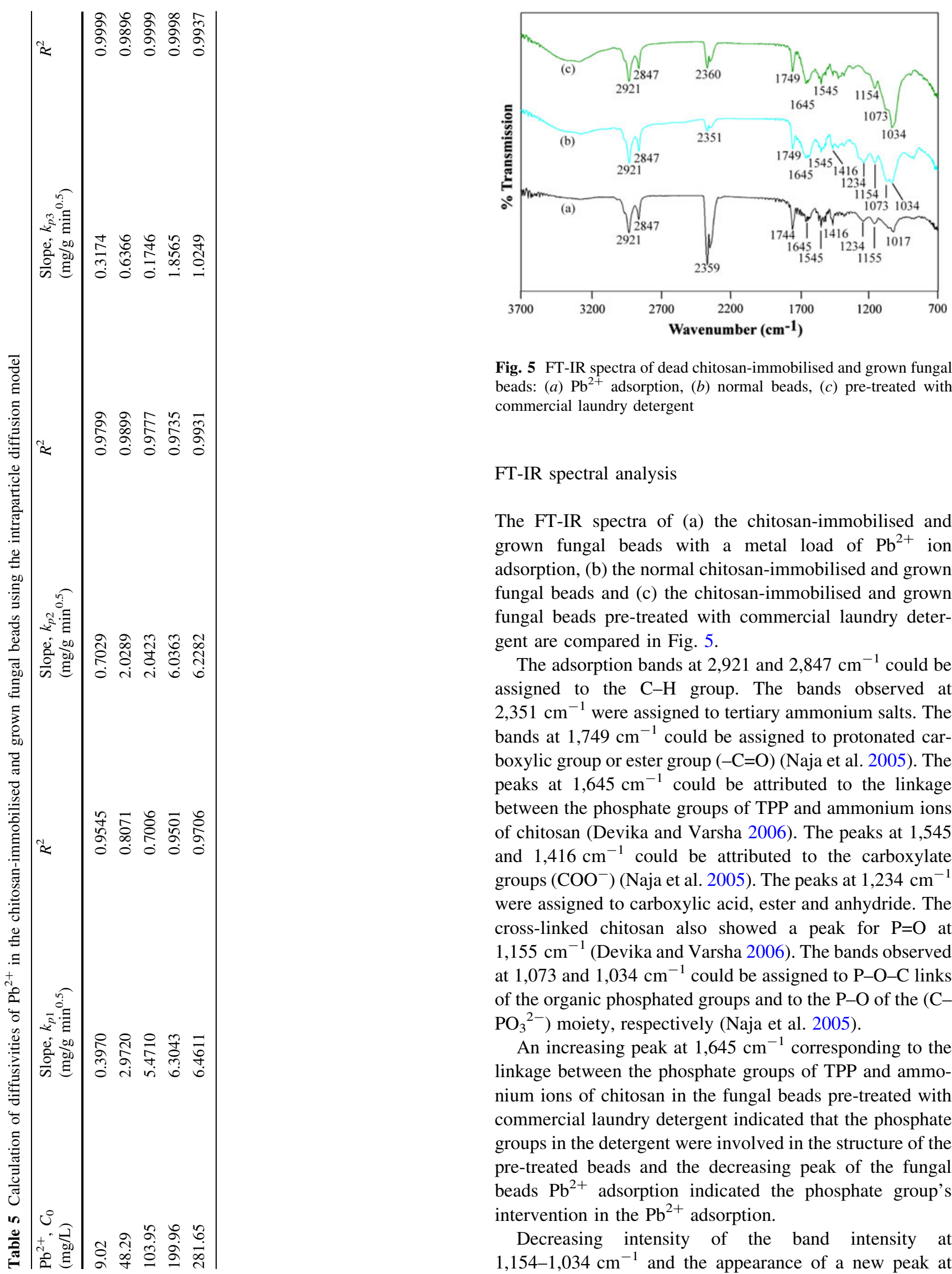

Fig. 5 FT-IR spectra of dead chitosan-immobilised and grown fungal beads: (a) $\mathrm{Pb}^{2+}$ adsorption, $(b)$ normal beads, (c) pre-treated with commercial laundry detergent

FT-IR spectral analysis

The FT-IR spectra of (a) the chitosan-immobilised and grown fungal beads with a metal load of $\mathrm{Pb}^{2+}$ ion adsorption, (b) the normal chitosan-immobilised and grown fungal beads and (c) the chitosan-immobilised and grown fungal beads pre-treated with commercial laundry detergent are compared in Fig. 5.

The adsorption bands at 2,921 and $2,847 \mathrm{~cm}^{-1}$ could be assigned to the $\mathrm{C}-\mathrm{H}$ group. The bands observed at $2,351 \mathrm{~cm}^{-1}$ were assigned to tertiary ammonium salts. The bands at $1,749 \mathrm{~cm}^{-1}$ could be assigned to protonated carboxylic group or ester group $(-\mathrm{C}=\mathrm{O})$ (Naja et al. 2005). The peaks at $1,645 \mathrm{~cm}^{-1}$ could be attributed to the linkage between the phosphate groups of TPP and ammonium ions of chitosan (Devika and Varsha 2006). The peaks at 1,545 and $1,416 \mathrm{~cm}^{-1}$ could be attributed to the carboxylate groups $\left(\mathrm{COO}^{-}\right)$(Naja et al. 2005). The peaks at $1,234 \mathrm{~cm}^{-1}$ were assigned to carboxylic acid, ester and anhydride. The cross-linked chitosan also showed a peak for $\mathrm{P}=\mathrm{O}$ at $1,155 \mathrm{~cm}^{-1}$ (Devika and Varsha 2006). The bands observed at 1,073 and $1,034 \mathrm{~cm}^{-1}$ could be assigned to $\mathrm{P}-\mathrm{O}-\mathrm{C}$ links of the organic phosphated groups and to the $\mathrm{P}-\mathrm{O}$ of the $(\mathrm{C}-$ $\mathrm{PO}_{3}{ }^{2-}$ ) moiety, respectively (Naja et al. 2005).

An increasing peak at $1,645 \mathrm{~cm}^{-1}$ corresponding to the linkage between the phosphate groups of TPP and ammonium ions of chitosan in the fungal beads pre-treated with commercial laundry detergent indicated that the phosphate groups in the detergent were involved in the structure of the pre-treated beads and the decreasing peak of the fungal beads $\mathrm{Pb}^{2+}$ adsorption indicated the phosphate group's intervention in the $\mathrm{Pb}^{2+}$ adsorption.

Decreasing intensity of the band intensity at $1,154-1,034 \mathrm{~cm}^{-1}$ and the appearance of a new peak at 
Table 6 Desorption of $\mathrm{Pb}^{2+}$ from the metal load of the chitosanimmobilised and grown fungal beads by various chemical agents (1 M)

\begin{tabular}{ll}
\hline Desorbing agent & \% Desorption of $\mathrm{Pb}^{2+}$ \\
\hline $\mathrm{HNO}_{3}$ & $97.55 \pm 0.17$ \\
$\mathrm{HCl}$ & $93.54 \pm 0.96$ \\
$\mathrm{EDTA}$ & $92.83 \pm 1.14$ \\
$\mathrm{H}_{2} \mathrm{SO}_{4}$ & $92.42 \pm 1.48$ \\
$\mathrm{NaOH}$ & $60.50 \pm 2.10$ \\
$\mathrm{Na}_{2} \mathrm{CO}_{3}$ & $55.83 \pm 1.36$ \\
$\mathrm{Deionised} \mathrm{water}_{\mathrm{CaCl}_{2}}$ & $15.59 \pm 0.79$ \\
\hline
\end{tabular}

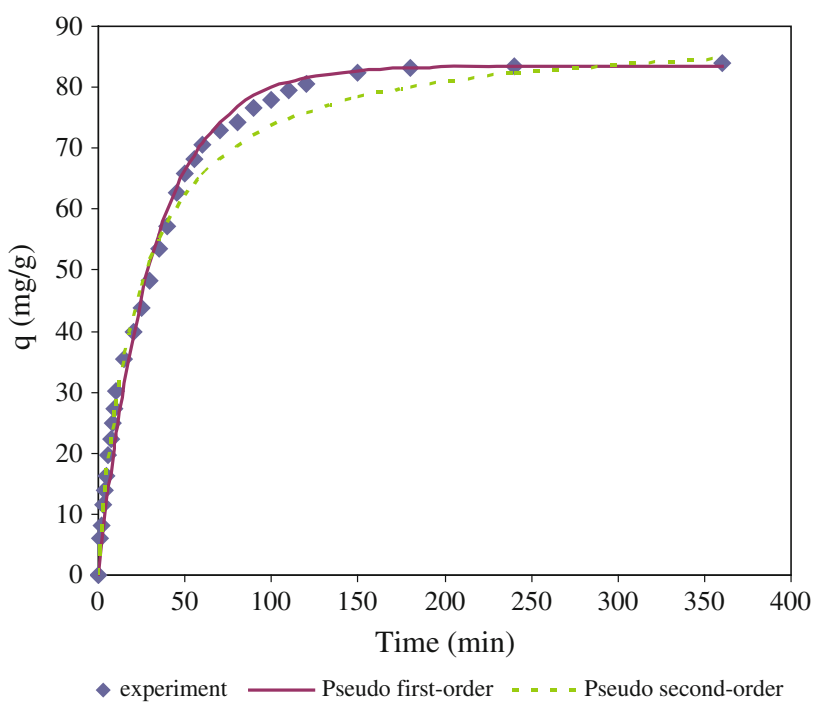

Fig. 6 Kinetics of $\mathrm{Pb}^{2+}$ desorption from the chitosan-immobilised and grown fungal beads at $30{ }^{\circ} \mathrm{C}$ with $1 \mathrm{M} \mathrm{HNO}_{3}$

$1,017 \mathrm{~cm}^{-1}$ and the disappearance of the peak $1,073 \mathrm{~cm}^{-1}$ indicated the phosphorus intervention in $\mathrm{Pb}^{2+}$ adsorption (Naja et al. 2005).

\section{Desorption and regeneration}

Eight different chemical agents tested for desorbing $\mathrm{Pb}^{2+}$ from the chitosan-immobilised and grown fungal beads are summarised in Table 6. The maximum desorption of $\mathrm{Pb}^{2+}$ occurred with $\mathrm{HNO}_{3}$ and $\mathrm{HCl}$ followed in decreasing order

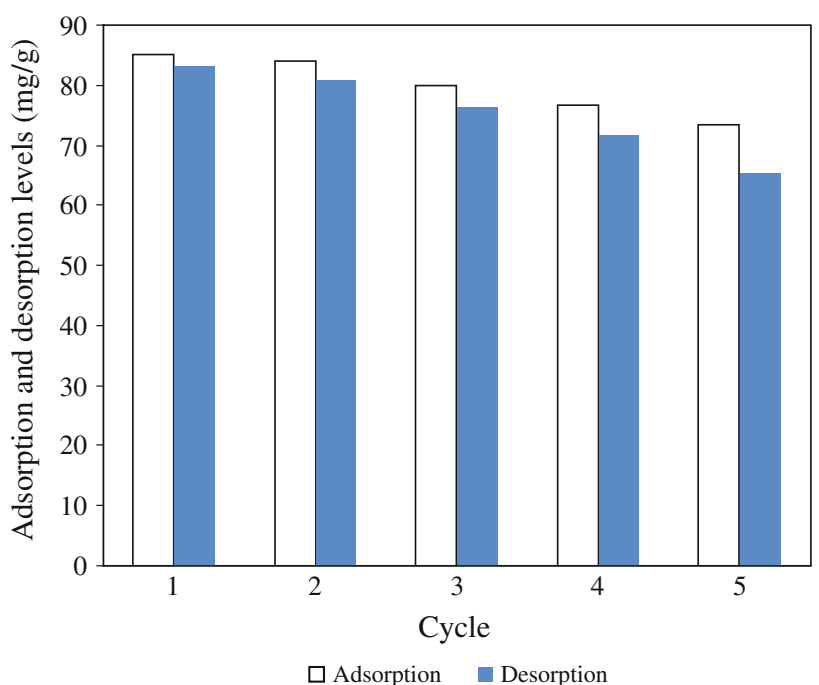

Fig. 7 Regeneration cycle of $\mathrm{Pb}^{2+}$ adsorption and desorption by the chitosan-immobilised and grown fungal beads at $30{ }^{\circ} \mathrm{C}$ during five consecutive cycles

by EDTA, $\mathrm{H}_{2} \mathrm{SO}_{4}, \mathrm{NaOH}, \mathrm{Na}_{2} \mathrm{CO}_{3}$, deionised water and $\mathrm{CaCl}_{2}$.

The non-linear regression models of pseudo first-order (Eq. 7) and pseudo second-order kinetics (Eq. 10) were used to fit the experimental data of $\mathrm{Pb}^{2+}$ desorption with $1 \mathrm{M} \mathrm{HNO}_{3}$ (Fig. 6). The results obtained from fitting these observations and their constants are summarised in Table 7. The coefficients of correlation, $R^{2}$, were used to determine the best fit between the experimental data and the modelling calculations of both models. The results showed that the data fit very well with both models for the desorption of $\mathrm{Pb}^{2+}$. The desorption system of $\mathrm{Pb}^{2+}$ on the green alga Pithophora oedogonia was reported to also be well modelled by both models (Singh et al. 2008). It is fairly well known that metal desorption mainly involves the process of ion exchange, in which protons or other ions of the desorbing agent replace metal ions from the binding sites (Metha and Guar 2005; Vijayraghavan et al. 2005).

To evaluate the repeatability of the chitosan-immobilised and grown fungal beads, the regeneration cycles of $\mathrm{Pb}^{2+}$ were repeated, with five cycles achieved by batch desorption using $1 \mathrm{M} \mathrm{HNO}_{3}$ as the desorbing solution. After five regenerations, the efficiency of attainable

Table 7 Kinetic constants and corresponding coefficients of determination for desorption of $\mathrm{Pb}^{2+}$ with $1 \mathrm{M} \mathrm{HNO}_{3}$ by the chitosan-immobilised and grown fungal beads after the first adsorption-desorption cycle using non-linearlised forms of pseudo first- and pseudo second-order models

\begin{tabular}{lllllll}
\hline Metal desorption & \multicolumn{3}{l}{ Pseudo first-order rate } & & \multicolumn{2}{l}{ Pseudo second-order rate (Ho and Mckay) } \\
\cline { 2 - 3 } & $\begin{array}{l}K_{1, D} \\
\left(\mathrm{~min}^{-1}\right)\end{array}$ & $\begin{array}{l}q_{e, D} \\
(\mathrm{mg} / \mathrm{g})\end{array}$ & $R^{2}$ & & $\begin{array}{l}K_{3, D} \\
(\mathrm{~g} / \mathrm{mg} \mathrm{min})\end{array}$ & $\begin{array}{l}q_{e, D} \\
(\mathrm{mg} / \mathrm{g})\end{array}$ \\
\hline $\mathrm{Pb}^{2+}$ & 0.0317 & 83.4219 & 0.9872 & & 0.0005 & 89.9643 \\
\hline
\end{tabular}


sorption and desorption of $\mathrm{Pb}^{2+}$ decreased to 13.72 and $21.43 \%$, respectively (Fig. 7). This showed that desorption of $\mathrm{Pb}^{2+}$ with $1 \mathrm{M} \mathrm{HNO}_{3}$ on the chitosan-immobilised and grown fungal beads could be repeatedly used in $\mathrm{Pb}^{2+}$ adsorption system practically five times with acceptable loss in adsorptive efficiency.

\section{Conclusion}

This study investigated biosorption as a function of $C_{0}$ for dead chitosan-immobilised and grown fungal beads. Chitosan is nontoxic to humans and has a low environmental impact. The results show that chitosan offers a possible alternative polymer matrix to immobilise viable fungal biomass using the resting spores. The beads pretreated with laundry detergent exhibited interestingly high capacity of $\mathrm{Pb}^{2+}$ biosorption for $381.23 \mathrm{mg} / \mathrm{g}$ in acidic condition. The Redlich-Peterson model was found to best describe the biosorption of $\mathrm{Pb}^{2+}$ when in equilibrium with the solution. However, the kinetic adsorption process, before equilibrium is reached, was in good agreement with the pseudo second-order Blanchard model. Meanwhile, based on the intraparticle diffusion kinetics, it can be concluded that the adsorption process follows macropore diffusion. The FT-IR spectra indicated that phosphate $\left(-\mathrm{PO}_{3}{ }^{2-}\right)$ and amine $(-\mathrm{NH})$ groups were the major binding sites of $\mathrm{Pb}^{2+}$. The advantages of this biosorbent were its rapid and high adsorption-desorption property and ability to be regenerated in at least five cycles.

Dynamic adsorption kinetics will be studied in the future to exploit the beads for lead-contaminated wastewater treatment.

Acknowledgments This work was supported by the Faculty of Liberal Arts and Science with a grant awarded in 2009 (FLAS.GR.WNL1.2009). The authors are grateful to Wilhelm J. Holzschuh of the Faculty of Liberal Arts and Science for proofreading the manuscript.

\section{References}

Akar T, Tunali S (2006) Biosorption characteristics of Aspergillus flavus biomass for removal of $\mathrm{Pb}$ (II) and $\mathrm{Cu}$ (II) ions from an aqueous solution. Bioresour Technol 97(15):1780-1787

Akpor OB, Muchie M (2010) Remediation of heavy metals in drinking water and wastewater treatment systems: processes and applications: review. Int J Phys Sci 5(12):1807-1817

Aksu Z (2001) Biosorption of reactive dyes by dried activated sludge: equilibrium and kinetic modeling. Biochem Eng J 7(1):79-84

Aksu Z, Balibek E (2007) Chromium(VI) biosorption by dried Rhizopus arrhizus: effect of salt $(\mathrm{NaCl})$ concentration on equilibrium and kinetic parameters. J. Hazard. Mat 145(1-2): 210-220

Aksu Z, Unsal A, Kutsal T (1997) Application of multicomponent adsorption isotherms to simultaneous biosorption of iron(III) and
chromium(VI) on Chlorella vulgaris. J Chem Tech Biotech 70(4):368-378

An HK, Park YB, Kim SD (2001) Crab shell for the removal of heavy metals from aqueous solution. Water Res 35(15):3551-3556

Arica MY, Arpa Ç, Ergene A, Bayramoğlu G, Genç Ö (2003) Caalginate as a supper for $\mathrm{Pb}^{2+}$ and $\mathrm{Zn}^{2+}$ biosorption with immobilised Phanerochaete chrysosporium. Carbohydr Polym 52(2):167-174

Bayramoğlu G, Arica YM (2006) Biosorption of benzidine based textile dyes "Direct Blue 1 and Direct Red using native and heattreated biomass of Trametes versicolor. J Hazard Mat 143(1-2): $135-143$

Blanchard G, Maunaye M, Martin G (1984) Removal of heavy-metals from water waters by means of natural zeolites. Water Res 18(12):1501-1507

Bossrez S, Remacle J, Goyette J (1997) Adsorption of nickel by Enterococcus hirae cell walls. Chem Tech Biotech 70(1):45-50

Bueno BYM, Torem ML, Molina F, de Mesquita LMS (2008) Biosorption of lead(II), chromium(III) and copper(II) by $R$. opacus: equilibrium and kinetic studies. Miner Eng 21(1):65-75

Crist RH, Martim JR, Chanko J, Crist DR (1996) Uptake of metals on peat moss: an ion-exchange process. Environ Sci Tech 30(8): 2456-2461

Deng L, Su Y, Su H, Wang X, Zhu X (2007) Sorption and desorption of lead(II) from wastewater by green algae Cladophora fascicularis. J Hazard Mat 143(1-2):220-225

Devika RB, Varsha BP (2006) Studies on effect of pH on crosslinking of chitosan with sodium tripolyphosphate: a technical note. AAPS Pharm Sci Tech 7(2):E138-E143

Friis N, Myers-Keith P (1986) Biosorption of uranium and lead by Streptomyces longwoodensis. Biotechnol Bioeng 28(1):21-28

Fritz W, Schlünder EV (1974) Simultaneous adsorption equilibria of organic solutes in dilute aqueous solutions on activated carbon. Chem Eng Sci 29(5):1279-1282

Gavrilescu M (2004) Removal of heavy metals from the environmental by biosorption. Eng Life Sci 4(3):219-232

Ghodbane I, Hamdaoui O (2008) Removal of mercury (II) from aqueous media using eucalyptus bark: kinetic and equilibrium studies. J Hazard Mat 160(2-3):301-309

Göksungur Y, Üren S, Güvenç U (2005) Biosorption of cadmium and lead ions by ethanol treated waste baker's yeast biomass. Bioresour Tech 96(1):103-109

Ho YS (2006) Review of second-order models for adsorption systems. J Hazard Mat 136(3):681-689

Ho YS, Mckay G (2000) The kinetics of adsorption of divalent metal ions onto sphagnum moss flat. Water Res 34(3):735-742

Holan ZR, Volesky B (1994) Biosorption of lead and nickel by biomass of marine algae. Biotechnol Bioeng 43(11):1001-1009

Huang CP, Blankenship DW (1984) The removal of mercury(II) from dilute aqueous solution by activated carbon. Water Res 18(1): $37-46$

Kapoor A, Viraraghavan T (1998) Biosorption of heavy metals on Aspergillus niger: effect of pretreatment. Bioresour Technol 63(2):109-113

Kumar KV (2007) Pseudo second-order models for the adsorption of safranin onto activated carbon: comparison of linear and nonlinear regression methods. J Harzard Mat 142(1-2):564-567

Lang W, Dejma C, Sirisansaneeyakul S, Sakairi N (2009) Biosorption of nonylphenol on dead biomass of Rhizopus arrhizus encapsulated in chitosan beads. Bioresour Tech 100(23):5616-5623

Metha SK, Guar JP (2005) Use of algae for removing heavy metal ions from wastewater: progress and prospects. Crit Rev Biotechnol 25(3):113-152

Muňoz Z, Moret A, Garcés S (2009) Assesment of chitosan for inhibition of Collectotrichum sp. on tomatoes and grapes. Crop Protect 28(1):36-40 
Nadavala KS, Swayampakula K, Boddu MV, Abburi K (2009) Biosorption of phenol and o-chlorophenol from aqueous solutions on to chitosan-calcium alginate blended beads. J Hazard Mat 162(1):482-489

Naja G, Mustin C, Berthelin J, Volesky B (2005) Lead biosorption study with Rhizopus arrhizus using a metal-based titration technique. J Colloid Interface Sci 292(2):537-543

Norton L, Baskaran K, Mckenzie T (2004) Biosorption of zinc from aqueous solutions using biosolids. Adv Environ Res 8(3-4): 629-635

Okoye IA, Ejikeme MP, Onukwuli DO (2010) Lead removal from wastewater using fluted pumpkin seed shell activated carbon: adsorption modelling and kinetics. Int J Environ Sci Tech 7(4): 793-800

Ozdemir G, Ozturk T, Ceyhan N, Isler R, Cosar T (2003) Heavy metal biosorption by biomass of Ochrobactrum anthropi producing exopolysaccharide in activated sludge. Bioresour Tech 90(1):71-74

Pino GH, Mesquita LMS, Torem ML, Pinto GAS (2006a) Biosorption of heavy metals by powder of green coconut shell. Sep Sci Tech 41(14):3141-3153

Pino GH, Mesquita LMS, Torem ML, Pinto GAS (2006b) Biosorption of cadmium by powder of green coconut shell. Min Eng 19(5):380-387

Pluemsab W, Fukazawa Y, Furuike T, Nodasaka Y, Sakairi N (2007) Cyclodextrin-linked alginate beads as supporting materials for Sphingomonas cloacae, a nonylphenol degrading bacteria. Bioresour Technol 98(11):2076-2081

Preetha B, Viruthagirl T (2007) Batch and continuous biosorption of chromium (VI) by Rhizopus arrhizus. Sep Purif Technol 57(1): 126-133

Preetha B, Viruthagirl T, Mohan SK (2003) Equilibrium and kinetic modelling: biosorption of nickel by Pseudomonas putida. Chem Eng World 38(9):87-89
Ritchie AG (1977) Alternative to the Elovich equation for the kinetics of adsorption of gases on solids. J Chem Soc Faraday Trans 73:1650-1653

Sag Y, Ozer D, Kutsal T (1995) A comparative study of the biosorption of lead(II) ions to Z. Ramigera and $R$. arrhizus. Process Biochem 30(2):169-174

Sari M, Tuzen M (2009) Kinetic and equilibrium studies of biosorption of $\mathrm{Pb}(\mathrm{II})$ and $\mathrm{Cd}(\mathrm{II})$ from aqueous solution by macrofungus (Amanita rubescens) biomass. J Hazard Mat 164(2-3):1004-1011

Sheng PX, Ting YP, Chen JP, Hong L (2004) Sorption of lead, copper, cadmium, zinc and nickel by marine algal biomass: characterization of biosorptive capacity and investigation of mechanisms. J Colloid Interface Sci 275(1):131-141

Singh A, Kumar D, Gaur JP (2008) Removal of Cu(II) and Pb(II) by Pithophora oedogonia: sorption, desorption and repeated use of the biomass. J Hazard Mat 152(3):1011-1019

Sobkowsk J, Czerwiński A (1974) Kinetics of carbon dioxide adsorption on a platinum electrode. J Electron Anal Chem 55(3):391-397

Tsezos M, Volosy B (1982) The mechanism of uranium biosorption by Rhizopus arrhizus. Biotech Bioeng 24(2):385-401

Vaughan T, Seo WC, Marshall EW (2001) Removal of selected metal ions from aqueous solution using modified corncobs. Bioresour Technol 78(2):133-139

Vijayraghavan K, Jegan J, Palanivelu K, Velan M (2005) Biosorption of cobalt(II) and nickel(II) by seaweeds: batch and column studies. Sep Purif Technol 44(1):53-59

World Health Organization (WHO) (2003) Guidelines for drinking water quality. WHO, Geneva (WHO/SDE/WSH 03. 04)

Yang XY, Al-Duri B (2005) Kinetic modeling of liquid-phase adsorption of reactive dyes on activated carbon. J Colloid Inter Sci 287(1):25-34 